\title{
A sociologia na prática de estudantes de Odontologia: tribos urbanas e saúde bucal
}

\author{
Vera Lúcia Ignácio Molina*; Enzo Rosetti*; Suely Carvalho Mutti Naressi* \\ * Faculdade de Odontologia da Universidade Estadual \\ Paulista - UNESP São José dos Campos
}

\section{RESUMO}

Esta experiência de ensino-aprendizagem revela como os universitários de um curso de odontologia experimentaram a aplicação da sociologia na prática social, junto a tribos urbanas e seus respectivos membros. A aproximação com a realidade urbana contemporânea iniciou-se com os conceitos ministrados em sala de aula, tais como: comunidade, cultura, agrupamentos sociais, tribos urbanas, processos sociais, diferenciações sociais, econômicas e culturais e bucalidade. Os primeiros contatos com as realidades possibilitaram o conhecimento dos líderes das tribos e a obtenção de informações gerais e específicas. Numa segunda etapa um questionário desenvolvido pelo professor foi aplicado para o delineamento do perfil socioeconômico e cultural. Num terceiro momento foi realizado "Indice Gohai". Os resultados indicaram que as equipes tiveram maior facilidade no entendimento dos conceitos e processos sociológicos e a prática social, da teoria da bucalidade; melhoraram as suas percepções dos conceitos de saúde coletiva através da vivência prática, tendo a tribo urbana como espaço de análise; delinearam o perfil socioeconômico da tribo urbana e determinaram o Índice de Gohai Geral que avalia a condição bucal e o grau de satisfação dos indivíduos das tribos com a mesma. Pela perspectiva didático-pedagógica este trabalho possibilitou aos alunos vivenci- arem as interfaces entre os campos teórico e prático das Ciências Sociais. As exposições das experiências práticas demonstraram que os objetivos definidos para a disciplina foram alcançados.

Descritores: Saúde coletiva. Processos sociais. Condição bucal.

\section{INTRODUÇÃO}

Entre os desafios que se impõem à prática docente no ensino superior se encontra aquela que se relaciona às articulações entre as ações didáticas, o ensinar e o aprender no contexto de sala de aula ${ }^{1}$.

É sabido que as situações didáticas propostas pelo modelo tradicional de ensino não são eficazes nem eficientes para levar o universitário a compreender os conteúdos específicos da Sociologia, por mais que estejam conectados à saúde bucal. Estas situações inibem o próprio docente, não levando o alunado a ser autônomo, e dessa forma, não compreendendo os conteúdos disciplinares específicos ${ }^{2}$.

Na busca pela inversão de papéis para um melhor aprendizado, urge a necessidade de transbordar do paradigma focado na ação didática universitária, substituindo a ênfase no ensino pela ênfase na aprendizagem; desta forma, é possível o transbordamento da centralidade no docente para o aluno, que desempenhará o papel central de sujeito e atuará para a ocorrência de sua aprendizagem,

Revista da ABENO • 15(1): 111-116, 2015. 
desenvolvendo habilidades e construindo o seu próprio conhecimento. O professor deixa de ser o agente transmissor para cumprir a função de mediador pedagógico no processo de aprendizagem do aluno ${ }^{3}$. A construção da autonomia se dá nas relações entre o conhecimento específico, a didática do docente e a articulação com os saberes que se complementam $^{4-6}$.

A ação didática universitária será inovadora na medida em que $o$ alunado se torna ativo no processo de ensino-aprendizagem, mas exige, também, que o docente elabore reflexões sobre sua prática pedagógica, reveja suas ações didáticas e encontre novas bases e descubra novos conhecimentos ${ }^{7}$.

Nesse sentido, a disciplina de Ciências Sociais Aplicadas à Saúde - concentração Sociologia, ao optar pelo aprender fazendo e pelo centrar na pessoa do aluno, usa a equipe de trabalho como estratégia para melhorar a efetividade do aprendizado e elevar o grau de satisfação de cada aluno.

A expressão "tribo urbana", utilizada como objeto de estudo dos alunos de graduação, foi cunhada pelo sociólogo francês Michel Maffesoli ${ }^{8}$, que começou a usá-la nos seus artigos a partir de 1985. São compostas por microgrupos sociais, cujos participantes possuem os mesmos hábitos, valores culturais, estilos musicais e ideologias políticas semelhantes. Algumas são alternativas à ordem social e se baseiam na organização da família, outras são apenas nomes genéricos dados a determinados grupos de pessoas. Todos os movimentos de contracultura são tribos urbanas, mas, nem todas as tribos urbanas são movimentos de contracultura ${ }^{9,10}$.

A razão da elaboração deste artigo provém da experiência de compreender as situações didáticas vivenciadas na sala de aula e o desafio de incluir na estrutura curri- cular de alunos de graduação em Odontologia a disciplina de Sociologia, relatando uma maneira de iniciar os estudos da mesma dentro do contexto da Saúde Bucal Coletiva, com a responsabilidade de levar o universitário a conquistar autonomia na compreensão dos conteúdos específicos da Sociologia, aplicando-os ao campo da saúde bucal. Esta reflexão relata o processo de ensinoaprendizagem utilizado com alunos do curso de Odontologia da Faculdade de Odontologia de São José dos Campos - Unesp, no ano de 2010, cursando o primeiro semestre.

\section{MÉTODOS}

Para a realização das atividades com os acadêmicos de graduação, delineou-se a seguinte sequência dinâmica de ação dos grupos:

- Escolha da tribo urbana a ser abordada pelo grupo de alunos; nesta etapa, cada equipe organizou a pesquisa bibliográfica sobre os conceitos sociológicos fundamentais: sociedade, cultura, grupos sociais e tribos sociais, e em seguida a pesquisa documental sobre a tribo de sua preferência. Desta etapa foi produzido um texto sobre os agrupamentos humanos e de forma particular, as características principais da tribo escolhida. Incluiu-se neste texto o relato sobre as observações empíricas realizadas e os primeiros contatos sobre seus membros;

- Coleta de dados referentes ao perfil sócio-econômico;

- Aplicação do Índice GOHAI;

- Tabulação dos resultados e construção de tabelas referentes ao perfil socioeconômico e à condição bucal;

- Apresentação de seminários, discussão e interação entre os grupos para trocas de experiências. 
A proposta didático-pedagógica foi sendo desenhada no transcorrer do semestre, e da avaliação da etapa anterior se propunha uma nova etapa. Os conteúdos foram sendo apresentados durante o primeiro semestre de 2010: Desigualdade Social, Estratificação Social, Sociedade, Comunidade, Grupos Sociais, Equipes de Trabalho, Tribos Urbanas, Relações Sociais de Produção. Estes conteúdos foram discutidos com o auxílio de recursos audiovisuais, textos de autores clássicos e atividades em pequenos grupos para fixar a aprendizagem. As atividades de ensinoaprendizagem ocorreram em oito fases distintas. Durante o ministrar dos conteúdos da disciplina, as atividades práticas eram construídas no entremear entre aprendizado e desenvolvimento dos trabalhos, colocando o conteúdo teórico em vigência. Cuidou-se para que cada conceito fosse operacionalizado de maneira a facilitar a observação sistemática, durante as visitas às tribos urbanas e no transcorrer de visitas aos sites das tribos urbanas.

Durante o começo das atividades letivas, as aulas da disciplina de Sociologia tive- ram como objetivo instrucional levar cada uma das equipes de trabalho a montar um quadro teórico sobre os conceitos de desigualdade social e saúde; os indicadores empíricos da desigualdade social; as formas de associação humana: grupos sociais e tribos urbanas, processos sociais, relações sociais; saúde bucal e Índice GOHAI.

Dessa forma, determinou-se a condição bucal por avaliação subjetiva - Índice GOHAI Geral - bem como a prevalência dos fatores relativos à dor e desconforto em relação aos dois outros. Adotou-se este índice devido aos estudantes estarem em fase inicial da graduação em Odontologia e, dessa forma, pouco familiarizados com indicadores epidemiológicos e noções elementares de doenças bucais. Esse índice também apresenta versatilidade para aplicação em diversos tipos de extratos sociais ${ }^{11}$, o que o torna interessante para a prática de percepção de saúde pelos alunos de graduação, durante a análise dos resultados.

O conteúdo programático, ao final tomou a seguinte estrutura demonstrada na Figura 1. 
Figura 1- Estrutura Final das Atividades de Aprendizagem

\begin{tabular}{|c|c|c|}
\hline \multicolumn{2}{|c|}{$\begin{array}{l}\text { Sociologia e Saúde Bucal } \\
\text { Fundamentos sociológicos: interação e associação humanas; grupo social, } \\
\text { equipe e tribo urbana. } \\
\text { Objeto de estudo da sociologia. } \\
\text { Aproximações entre a sociologia, a saúde e a saúde bucal. } \\
\text { Cultura e Sociedade }\end{array}$} & \multirow[t]{2}{*}{$\begin{array}{l}\text { Metodologia de Ensino } \\
\text { Projeção de videos sobre os } \\
\text { conceitos sociológicos } \\
\text { fundamentais. }\end{array}$} \\
\hline \multicolumn{2}{|c|}{$\downarrow$} & \\
\hline \multicolumn{2}{|c|}{$\begin{array}{c}\text { Estrutura e Organização da sociedade capitalista } \\
\text { Sociedade Capitalista: as classes sociais. } \\
\text { Especificidades e Particularidades da sociedade brasileira: as classes sociais } \\
\text { brasileiras e relações de classes. } \\
\text { Modelos de determinação de classes sociais. } \\
\text { Relações entre o Estado e a Sociedade Brasileira. } \\
\text { Sistema Único de Saúde e a Politica Social de Saúde. } \\
\text { SUS e os princípios filosóficos e operacionais. } \\
\text { SUS e as estratégias em saúde e saúde bucal. } \\
\text { Politica Nacional de Saúde Bucal. }\end{array}$} & \multirow[b]{3}{*}{$\begin{array}{l}\text { Atividades em pequenos grupos } \\
\text { para fixação da aprendizagem. }\end{array}$} \\
\hline \multicolumn{2}{|l|}{$\downarrow$} & \\
\hline \multicolumn{2}{|l|}{$\begin{array}{c}\text { Tribo Urbana } \\
\text { Levantamento das referências bibliográficas sobre trib } \\
\text { Elementos distintivos das tribos urbanas. } \\
\text { Caracteristicas da tribo urbana. } \\
\text { Exemplos de tribos urbanas. }\end{array}$} & \\
\hline \multicolumn{3}{|c|}{$\begin{array}{c}\text { Fazer para Aprender } \\
\text { Divisão da turma em equipes de trabalho. } \\
\text { Atividade } 01-\text { Selecionar e justificar a tribo urbana, como objeto de análise. } \\
\text { Atividade } 02 \text { - Organizar um texto sobre tribo urbana. } \\
\text { Atividade } 03 \text { - Organizar um texto sobre a tribo urbana selecionada. } \\
\text { Atividade } 04 \text { - Descrever modos de vida, comportamento e dieta. }\end{array}$} \\
\hline & & $\nabla$ \\
\hline \multirow{2}{*}{$\begin{array}{l}\text { Trabalho de Campo } \\
\text { Fase I - Aproximação e Conhecimento da tribo urbana: } \\
\text { conversas, fotografias, caracteristicas particulares, modo } \\
\text { e estilo de vida. }\end{array}$} & \multicolumn{2}{|c|}{$\begin{array}{l}\text { Trabalho de sala de aula } \\
\text { Fase I - Elaboração do texto sobre o que e as } \\
\text { característica da tribo urbana selecionada. }\end{array}$} \\
\hline & & $\downarrow$ \\
\hline $\begin{array}{c}\text { Trabalho de Campo } \\
\text { Fase II - Delineamento do perfil socioeconômico }\end{array}$ & \multicolumn{2}{|c|}{$\begin{array}{l}\text { Trabalho de sala de aula } \\
\text { Fase II - Delineamento do perfil socioeconômico } \\
\text { Organização dos dados em tabela única. } \\
\text { Elaboração do texto descrevendo os dados. }\end{array}$} \\
\hline Aplicação do questionário elaborado pelo professor. & 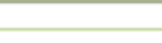 & $\downarrow$ \\
\hline $\begin{array}{l}\text { Trabalho de Campo } \\
\text { Fase III - Aplicação do Teste de Gohai }\end{array}$ & \multicolumn{2}{|c|}{$\begin{array}{l}\text { Trabalho de sala de aula } \\
\text { Fase III- Definição da classe social dos membros da tribo } \\
\text { urbana } \\
\text { Aplicação do modelo de Silva (classificação pela } \\
\text { ocupação). Elaboração do texto sobre a classe social. }\end{array}$} \\
\hline & & $\nabla$ \\
\hline \multicolumn{3}{|c|}{$\begin{array}{l}\text { Trabalho de sala de aula } \\
\text { Fase IV - Organização dos dados } \\
\text { Fase V - Cálculo para determinação do indice de condição bucal. Comparação da condição bucal pelos fatores: fisicos- } \\
\text { mecânicos; psicossocial, relativos à dor. } \\
\text { Fase VI - Discussão dos resultados, a partir de um roteiro de questões proposto pelo professor. } \\
\text { Fase VII - Considerações Finais }\end{array}$} \\
\hline
\end{tabular}

\section{SÍNTESE DOS DADOS}

A expressão "tribo urbana" foi cunhada pelo sociólogo francês Michel Maffesoli, que começou usá-la nos seus artigos a partir de 1985. A expressão ganha força três anos depois com a publicação do seu livro "Le temps des tribus: le déclin de l'individualisme dans les sociétés postmodernes"; são compostas por micro grupos sociais, cujos participantes possuem os mesmos hábitos,

Revista da ABENO • 15(1): 110-118, 2015. 
valores culturais, estilos musicais e ideologias políticas semelhantes. Algumas são alternativas à ordem social e se baseiam na organização da família, outras são apenas nomes genéricos dados a determinados grupos de pessoas $^{8-10}$. Todos os movimentos de contracultura são tribos urbanas, mas, nem todas as tribos urbanas são movimentos de contracultura.

Diversos grupos parecem ter saído das histórias de revistas em quadrinhos para a vida real, enquanto outros são sensíveis e introspectivos, e há aqueles que incluem os admiradores das novas tecnologias e os adeptos de uma filosofia de vida de preservação dos direitos dos animais ${ }^{12}$.

As tribos urbanas não existem para criarem maior aliança dentro da sociedade, mas sim para se distinguirem dentro dela. Hoje esses grupos são caracterizados pelos indivíduos que se expressam de alguma maneira original e, muitas vezes, incomum. Seus membros compartilham de afinidades e muitas delas chegam a formar uma cultura própria, que é reconhecida por seus símbolos, por sua linguagem própria, com gírias e expressões, pelo estilo musical, pelos tipos de roupas, costumes, rituais, entre outros. As tribos jovens, como também são conhecidas, costumam andar em bandos em busca do encontro, do proibido, do prazer e de diversão ${ }^{13-15}$.

Segundo Tessari, os jovens se reúnem em tribos por necessidade de buscarem valores e modelos de mundo. A inserção em tribos se dá na adolescência, momento de construção da própria identidade e é quando negam certos valores para experimentarem novas situações ${ }^{16}$.

Não possuem um projeto específico, normalmente são pessoas que se encontram em momentos de descontração, para conver- sar, praticar algum esporte, trocar informações sobre seu meio em comum e para fazer novas amizades. Porém, muitas delas acabam sendo rotuladas, principalmente por pessoas que não têm nenhum conhecimento sobre determinadas tribos.

Os fenômenos das tribos urbanas se constituem "nas diversas redes, grupos de afinidades e de interesse, laços de vizinhança que estruturam nossas megalópoles. Seja qual for o que está em jogo é a potência contra o poder, mesmo que aquela não possa avançar senão mascarada para não ser esmagada por este"8.

Mantêm viva a capacidade de resistir e contestar a morte da identidade pessoal, promovida pela sociedade moderna. O sentimento de vazio e de descontentamento vivido pelo jovem de hoje pode levar a uma resistência diante do mundo opressor, massificador e destruidor de personalidades. As tribos urbanas mantêm em alta a pluralidade de opções e de estilos de vida, contribuindo para a felicidade e construção do indivíduo. Elas são politizadas, mas não se opõem frontalmente ao poder político estabelecido e utilizam, por exemplo, a música para afirmar sua não adesão aos ideais dos mantedores da ordem.

Alguns aspectos presentes na dinâmica social são tidos como negativos, pois se fecham entre si e acabam por não aprender com o que vem de fora ${ }^{14}$. Esta segregação tornam as tribos improdutivas, visto que não existem trocas de valores culturais entre elas. Em muitos casos ocorre rivalidade e as brigas são constantes e comuns. Outro fato importante está no preconceito por parte de cidadãos não pertencentes a nenhuma tribo.

Entre as características da tribo urbana se destacam $^{8}$ : o não ativismo (uma vez que o neotribalismo não se opõe frontalmente 
ao poder político). Isto não quer dizer, no entanto, que as tribos urbanas sejam passivas ou que não prestem atenção ao jogo político. O que fazem é evitar as formas institucionalizadas de protesto. A resistência é mais subterrânea, valendo-se, por exemplo, da música para afirmar sua não adesão à "assepsia social" dos mantenedores da ordem. Fluidez Estabilidade: São instáveis e abertas. Uma pessoa pode evoluir de uma tribo para outra. Proxemia: Sentimento de pertença. Cultura Informal: Estes grupos não têm projetos específicos a não ser o compartilhamento, o aqui e o agora $^{13}$.

As visitas aos sites das tribos urbanas selecionadas, os primeiros contatos com seus membros e as primeiras conversas permitiram que cada equipe de trabalho apresentasse um relatório sobre a tribo urbana em seu contexto histórico-social, estilo de vida, valores socioculturais, crenças e rituais.

A experiência de ensinoaprendizagem aqui relatada revela como os universitários de um curso de odontologia experimentaram a aplicação prática da sociologia na identificação socioeconômica, cultural e a condição bucal por auto-avaliação de indivíduos pertencentes a determinadas tribos urbanas.

Teve-se como ponto de partida o enfoque histórico-crítico e analítico, para se evitar inúmeros equívocos. As análises realizadas pelas Ciências Sociais exigem o respeito ao nível de aprofundamento que se pretende. A análise foi realizada na realidade concreta e específica de cada tribo. Neste estudo, o nível de abstração foi dado pela tribo urbana, o nível conjuntural, os processos relacionados com detalhes institucionais. A análise contou, então, como um nível concreto e específico: a tribo urbana; e se tratou também de uma microanálise, pois tratou-se da posi- ção da tribo urbana, em que cada membro está sujeito a um conjunto de mecanismos ligados à estrutura da tribo a qual pertence e à situação de classe social. A unidade de análise são as pessoas no interior da tribo urbana; dessa forma, a análise torna-se micro. Os membros fazem acordos, concordam "em que jogo devem jogar”, e podem discordar das regras.

Dentro desta linha de raciocínio, a formação do acadêmico de Odontologia deve ser voltada também com o olhar crítico sobre as transformações sociais e culturais, estando atento ao comportamento de determinados grupos e seus respectivos hábitos que possam influenciar na saúde bucal dos indivíduos que os permeiam. Possuirão um importante papel de instruir e colaborar para a prevenção e promoção de saúde bucal de uma pessoa, através de atividades preventivas, práticas higiênicas, manutenção, motivação e suporte. Assim, os cidadãos integram o princípio da integralidade através do enxergar de si próprio como principal responsável de sua saúde geral, incluindo a saúde bucal, como já propriamente dito. Dessa forma, um indivíduo que promove a sua própria saúde bucal e socializa-se com os demais indivíduos do meio em que vive está promovendo a "bucalidade”, sendo este um conceito em que uma boca não deve ser segregada do resto do corpo, e sim pertence a uma pessoa que convive e permeia o âmbito social aonde reside, sendo parte de um contexto bio-psico-social. De toda forma, a bucalidade é entendida como expressão dos trabalhos sociais que a boca humana realiza, mostrando, portanto, que a boca não se encontra isolada, mas sim dentro de um corpo, que é resultado do biológico, psíquico e afetivo ${ }^{17}$.

Com este estudo, as equipes puderam verificar como as tribos se organizam. Em 
geral cada membro no interior da tribo urbana ocupa uma determinada posição social e desempenha múltiplos papéis, e um número considerável de interação face a face, tomam conhecimento dos símbolos culturais relevantes, experimentam emoções e se autoavaliam. As tribos com menor número de membros maior é a capacidade de influenciar seus membros ao longo de muitas dimensões.

Entre os processos sociais evidenciados se encontram a liderança, a tomada de decisões de forma coletiva, a coesão, a solidariedade e a expectativa. Sejam os líderes de tarefas e líderes sócio emocionais, buscam orientar os membros para o alcance dos objetivos e aliviar tensões. A tomada de decisão coletiva é mais decisiva e reforça a coesão e a solidariedade ${ }^{13}$. A quantidade de membros aumenta a coesão e solidariedade favorecendo a harmonia e tornando os membros mais seguros. A solidariedade é um dos aspectos centrais na manutenção da tribo, já que este processo faz emergir a disposição dos membros individuais a apoiarem as lutas, participarem ativamente dos projetos para que a tribo conquiste determinado fim coletivamente desejado. Perceberam também que a solidariedade assume diferentes formas, define os processos sociais associativos e dissociativos, e depende da liderança, dos ativistas e da própria organização.

O desempenho de papéis de forma específica cria expectativas de que futuros comportamentos serão interpretados dessa maneira. Elas são observadas pelos olhares e antecipação dos outros ou por seu desapontamento se não forem correspondidos às suposições. Esta pressão impulsiona a manutenção dos papeis e suas formas de desempenho.

\section{CONSIDERAÇÕES FINAIS}

Trazer as tribos urbanas como conteúdo transversal para a disciplina de Sociologia possibilitou uma situação de ensinoaprendizagem que incentivasse os alunos a reconhecerem a relevância dos processos sociais, das relações sociais, da questão das desigualdades sociais nos estudos sobre saúde bucal coletiva e do contexto históricosocial.

Os objetivos deste estudo transversal levaram os acadêmicos de tal Instituição a relacionarem o perfil socioeconômico às condições da saúde bucal de um conjunto de cidadãos, pertencentes às diferentes tribos urbanas e o uso dos resultados para consequente elaboração de programa e ações voltadas para a Saúde Bucal Coletiva.

Pela perspectiva didáticopedagógica, este trabalho possibilitou aos alunos do primeiro ano vivenciar as interfaces entre os campos teórico e prático das Ciências Sociais. A procura dos conceitos sociológicos dados, dos estudos sobre a tribo urbana, o estilo de vida e os processos sociais, a situação social, a condição bucal e contato com a realidade empírica dos membros das tribos urbanas, foram os objetivos definidos para a disciplina e foram alcançados.

Embora o sistema de desigualdade social tenha sido tratado durante as aulas e a classificação socioeconômica para o Brasil tenham sido exemplificados, o alcance do entendimento da estrutura social do conceito de tribo urbana na sociedade brasileira ainda apresenta-se muito complexo, exigindo uma demanda maior de carga horária para ensino e apresentação de aprofundamento disciplinar teórico para os acadêmicos. 


\section{REFERÊNCIAS}

1. Althaus MTM. Ação didática no ensino superior: a docência em discussão. Rev. Teoria e Prática da Educação. 2004;7(1):101-6.

2. Teixeira M. Prática docente e autonomia do aluno: uma relação a ser construída nos cursos de graduação. (Dissertação) Pontifícia Universidade Católica de São Paulo, 2002.

3. Lucarelli E. Um desafio institucional: inovação e formação pedagógica do docente universitário. In: Castanho S, Castanho MELM (Orgs.). O que há de novo na educação superior: do projeto pedagógico à prática transformadora. Campinas, Papirus, 2000.

4. Pimenta SG. De professor e didática. Campinas: Papirus, 2002.

5. Pimenta SG. (org.). Saberes Pedagógicos e atividade docente. 3. ed. São Paulo: Cortez, 2002.

6. Teixeira M. Prática docente e autonomia do aluno: uma relação a ser construída nos cursos de graduação. (Dissertação) Pontifícia Universidade Católica de São Paulo, 2002.

7. Santos JAF. Uma classificação socioeconômica para o Brasil. RBCS. 2005;20(58):27-46.

8. Maffesoli M. O tempo das tribos: o declínio do individualismo nas sociedades de massa. Rio de Janeiro: Forense Universitária, 1998.

9. Maffesoli, M. Sobre nomadismo: vagabundagens pós-modernas. Rio de Janeiro: Record, 2001.

10. Maffesoli, M. Notas sobre a pósmodernidade: o lugar faz o elo. Rio de Janeiro: Atlântica, 2004.

11. Guzeldemir E, Toygar HU, Tasdelen B, Torun D. Oral health related quality of life and periodontal health status in patients undergoing hemodialysis. J Am Dent Assoc. 2009;140:1283-93.

12. Silva SED, Padilha MI. O perfil de adolescentes das tribos urbanas/PA: implicações para as representações sociais. G\&S. 2013;4:1894-910.

13. Barroso PF. Redes de solidariedade entre vendedores ambulantes da Rua Voluntários da Pátria, em Porto Alegre/RS. Iluminuras. 2012;13:236-59.

14. Silva VC, Couto ES. Interfaceamentos contemporâneos: tecnologias digitais e tribos urbanas no contexto escolar. Educ Rev. 2012;28(2):333-46.

15. Pais JM. Grupos e afiliações sociais. Revista Teias, 2011; 12(26):247-86.

16. Tessari O. Jovens buscam identidade. www.olgatessari.com.br. Acesso: 1 maio, 2010.

17. Botazzo C. Da Arte Dentária. São Paulo: Hucitec, 2000.

\section{ABSTRACT \\ Urban tribes and oral health: a sociologi- cal experience in a school of dentistry}

This educational experience shows how dental students deal with sociology application on the practical field, such as urban tribes and its human components. The dental students began to getting closer with practical field by attending the sociological concepts, such as community; cultures; social groups; urban tribes; social processes; social, economic and cultural contrasts; "bucality". The first contact with urban tribes and their own realities was important to know about urban tribes leaders, such as general and specific information about them. In a second period, a questionnaire was developed by the professor to be applied for discovering the actual soci- 
oeconomic and cultural profile of the tribe. In a third moment, it was used the GOHAI Index. The results showed that this way of teaching sociology was more effective and comprehensive to students, due to practical field of sociological processes and "bucality" theory; also, they improved their perceptions about public health basic concepts beyond practical field, in which the urban tribes were questioned. Dental students were able to percept the socioeconomic profile for each urban tribe and determinate the GOHAI Index, that evaluates oral conditions by selfperception of their human components. Considering the sociological and public health impact, this teaching-learning experience gave to dental students a opportunity to vivenciate it on a practical field, contemplating the proposals of the applied sociology subject.

Descriptors: Public Health. Social Processes. Oral Health.

Correspondência para:

Enzo Rosetti

e-mail: enzorosetti@gmail.com

Av. Engenheiro Francisco José Longo, 777

Jardim São Dimas 12245-000 - São José dos

Campos/SP 